\title{
Assessment of Nurses Knowledge Who Working in Premature Section about Ideal Nursing Care at Kerbala Pediatric Teaching Hospital, Iraq, 2020
}

\author{
Gahda Ali Hashim \\ BSN, Maternal and Neonatal, College of Nursing, University of Kerbala, Kerbala City, Iraq
}

\begin{abstract}
Objectives: To determine assessing the nurse knowledge towards ideal nursing care for premature baby.

Methodology: A descriptive quantitative study was carried out in order to achieve the early stated objectives. The study was initiated from

$10^{\text {th }}$ february, 2019; to $10^{\text {th }}$ july, 2019. The study was conducted at kerbala pediatric teaching hospital. A non-probability (purposive sample) of 41 nurses, who work in premature care unit at kerbala pediatric teaching hospital.

Result: The study show high percentage 61\% related to item (21-30) years .Regarding years of experience was $53.7 \%$. Regarding educational level was $70.7 \%$ for junior nursing . Regarding complication of premature baby the high percentage was $97.33 \%$ related to item "fingernails and toenails are abnormally delicate and short ".Regarding nursing care high percentage was 98.33 for item "the mother must breast feed her baby to avoid jaundice".

Conclusion: According to the present study findings, the researchers enabled to make the following conclusions: most of the nurses participated in the study were female,within age group less than 30 years old. The majority of nurses that participated in this study have a secondary school of qualification in nursing, the majority of the nurses who is working in premature department within less than five years of experience in premature unit. The study revealed high percentage regarding nursing care of premature baby.

Conclusions and Recommendations: According to the present study findings, the researchers enabled to make the following conclusions: Most of the nurses participated in the study were female, within age group less than 30 years old. The majority of nurses that participated in this study have a secondary school of qualification in nursing. Most of nurse working in premature department, and the majority of them within less than five years of experience in premature unit,Most of nurses participated in training sessions regarding management of premature. The study revealed high nurse's knowledge regarding caring of premature baby. According to the results of the study the researcher recommended that: Emphasis on the survival of nurses working in the department where they work and not to change their section of work in order to allow time to gain more experience in the section increase information. Emphasize the establishment of scientific courses for the nurses who work in the department so that they can gain more experience. Provision of scientific booklet about standard management with clear language. College graduated nurses should be encouraged to working in premature department.
\end{abstract}

Keywords: Nurses knowledge, premature, ideal nursing care.

\section{Introduction}

The birth of a baby is a wonderful yet very complex process. Many physical and emotional changes occur for mother and baby. A baby must make many physical adjustment to life outside the mother's body (Narinder, 2004).Leaving the uterus means that a baby 
can no longer depend on the mother's circulation and placenta for important physiologic functions. Such as (breathing,eating,elimination of wast,and immunologic protection) (Narinder, 2004).Suraj C(2010) mention that a baby when enters the world, many body systems change dramatically from the way they functioned during fetal life e.g. (The lungs must breathe air,The cardiac and pulmonary circulation changes. The digestive system must begin working to balance fluids and chemicals in the body and excrete waste, The liver and immunologic systems must begin functioning independently. The baby's body systems must work together in a new way. Sometimes, a baby has difficulty making the transition to the world. Being born prematurely, having a difficult delivery or birth defects can make these changes more challenging.Fortunately for these babies, special newborn care is necessary so he needed the incubator. Incubator is an apparatus for maintaining an newborn (especially premature infant) in an environment of controlling temperature, humidity, and oxygen concentration so it's provides a clean environment and help to protect the baby from noise, infection, and excessine handling so the nurse should be careful handling with infant and incubator to promote infant health (Suraj G.,2010)

Preterm infants are at great risk for medical complications and future developmental disabilities. They can develop a range of problems, their organs are not mature and an unfavorable environment in the neonatal intensive care unit, may compound this morbidity. It has been recognized that for many years the environment of neonatal intensive care unit can have an important influence on the development of premature infants (Aita \& Sinder, 2003).

\section{Methodology}

A descriptive quantitative study was carried out in order to achieve the early stated objectives. The study was initiated from $10^{\text {th }}$ february, 2019; to $10^{\text {th }}$ july, 2019. The study was conducted at kerbala pediatric teaching hospital.

The Sample of the Study was non-probability (purposive sample) of 41 nurses, whose work in premature care unit at kerbala pediatric teaching hospital. The data were collected through the utilization of the structured questionnaire and by means of interviewing technique with the subjects who were individually interviewed in the premature child at hospital teaching kerbala by the using the Arabic version of the questionnaire, and they were interviewed in a similar way, in the same place. After reviewing the related literatures and relevant studies, a draft instrument was developed by the researchers. Astructured questionnaires consisting of closed ended questions were distributed to nurses at time of data collection. It consist from two main part as follow: Part one of study instrument represent the socio-demographic data, that consist of (9) items, which include age, gender, marital status, qualification, working setting [premature child unit] total years of experience, years of experience in premature child unit. The second part of the questionnaire was consist from three section; section one consist from (20) items that are related to nurses knowledge regarding pediatric child unit and its risk factors; section two consist from (15) items regarding to nurses knowledge regarding signs and symptoms and diagnostic procedures of premature child unit. The items have been rated and scored according to the following patterns:

1. Three point likert scale was used to test the respondent knowledge of each question that was scored with (3) for agree, (2) for uncertain, and (1) for disagree.

2. The higher grade scoring of the questionnaire (MS), (RS) the greater level of knowledge regarding caring of premature child.

3. Each question consists of (3) alternative responses, and only one of these alternative responses was considered a correct response. To achieve the purpose of the present study, the responses of knowledge questionnaire were scored as (3) foragree, (2) for uncertain and (1) for disagree. The cut of point was (2) and the low limit for acceptance nurses knowledge was (66.6), the relative sufficiency (RS) for acceptance of nurses knowledge score was calculated according to the following formula: (Cut of point) $x 100 /$ (No. of scale).

Low $=($ less than 66.6 $)$, Moderate $=(66.6-83.3)$, High $=(83.3-100)$, these calculated according to the following formula $(100-66.6) / 2=16.7$, then this score was added to $(66.6+16.7=83.3)$ moderate level, $(83.3+16.7=100)$ high (AL-Maliky, 2010).

In addition to the experts' responses, their suggestions were taken into consideration. So far, modifications are employed and the final copy of the constructed instrument is completed to be an appropriate 
tool for conducting the study. The pilot study was conducted from 12 - 13 Joun 2019. Reliability of the studied questionnaire was $(0.85)$ by using Cronbach Alpha test. All data was analyzed using the statistical package for social science (SPSS) for Windows version 20. The statistical procedures, which are applied for the data analysis and assessment of the results, included the following: (a) Statistical tables includes Frequencies (F), Percentages (\%), cumulative percents, mean of score (M.S), were used to summarize the data.

(b) Relative sufficiency (R.S): was assess for level of knowledge by three grades (Low, Moderate, and High).

\section{Results}

Table (1) Participants nursing care $(n=41)$.

\begin{tabular}{|c|c|c|c|c|c|c|c|}
\hline \multirow[b]{2}{*}{ No } & \multirow[b]{2}{*}{ Item } & \multicolumn{6}{|c|}{ Response Answer } \\
\hline & & & $\mathbf{F}$ & $\mathbf{P}$ & m.s. & r.s. & $\begin{array}{c}\text { Level of } \\
\text { knowledge }\end{array}$ \\
\hline \multirow{3}{*}{1} & \multirow{3}{*}{$\begin{array}{l}\text { the temperature of the incubator must ranging between }(20,30) \text { and } \\
\text { the perfect humidity ranging for }(40 \%, 50 \%)\end{array}$} & Disagree & 3 & 7.3 & \multirow{3}{*}{2.80} & \multirow{3}{*}{93.33} & \multirow{3}{*}{$\mathrm{H}$} \\
\hline & & Uncertain & 2 & 4.9 & & & \\
\hline & & Agree & 36 & 87.8 & & & \\
\hline \multirow{3}{*}{2} & \multirow{3}{*}{ the mother must breast feed her baby to avoid jaundice } & Disagree & 1 & 2.4 & \multirow{3}{*}{2.95} & \multirow{3}{*}{98.33} & \multirow{3}{*}{$\mathrm{H}$} \\
\hline & & Uncertain & 0 & 0 & & & \\
\hline & & Agree & 40 & 97.6 & & & \\
\hline \multirow{3}{*}{3} & \multirow{3}{*}{ vitamins must be given to the premature baby } & Disagree & 1 & 2.4 & \multirow{3}{*}{2.82} & \multirow{3}{*}{94} & \multirow{3}{*}{$\mathrm{H}$} \\
\hline & & Uncertain & 5 & 12.2 & & & \\
\hline & & Agree & 35 & 85.4 & & & \\
\hline \multirow{3}{*}{4} & \multirow{3}{*}{$\begin{array}{l}\text { breast-feeding begins immediately from birth to avoid } \\
\text { hypoglycemia or high bilirubin }\end{array}$} & Disagree & 2 & 4.9 & \multirow{3}{*}{2.90} & \multirow{3}{*}{96.66} & \multirow{3}{*}{$\mathrm{H}$} \\
\hline & & Uncertain & 0 & 0 & & & \\
\hline & & Agree & 39 & 95.1 & & & \\
\hline \multirow{3}{*}{5} & \multirow{3}{*}{ breast-feeding protects the child from gastroenteritis } & Disagree & 1 & 2.4 & \multirow{3}{*}{2.90} & \multirow{3}{*}{96.66} & \multirow{3}{*}{$\mathrm{H}$} \\
\hline & & Uncertain & 2 & 4.9 & & & \\
\hline & & Agree & 38 & 92.7 & & & \\
\hline \multirow{3}{*}{6} & \multirow{3}{*}{$\begin{array}{l}\text { sweeping child's body by alcohol help reduce the baby's } \\
\text { temperature }\end{array}$} & Disagree & 2 & 4.9 & \multirow{3}{*}{2.75} & & \\
\hline & & Uncertain & 6 & 14.6 & & 91.66 & $\mathrm{H}$ \\
\hline & & Agree & 33 & 80.5 & & & \\
\hline & & Disagree & 2 & 4.9 & & & \\
\hline 7 & $\begin{array}{l}\text { the best time for newborn baby shower when the child's } \\
\text { temperature is stable }\end{array}$ & Uncertain & 2 & 4.9 & 2.85 & 95 & $\mathrm{H}$ \\
\hline & & Agree & 37 & 90.2 & & & \\
\hline & if the incubator is not available the heat can be provided by rolling & Disagree & 3 & 7.3 & & & \\
\hline 8 & the child and placing a warm water by around him or shedding & Uncertain & 6 & 14.6 & 2.48 & 82.66 & $\mathrm{H}$ \\
\hline & light near him & Agree & 32 & 78.0 & & & \\
\hline & & Disagree & 8 & 19.5 & & & \\
\hline 9 & put a blank made of fiber under the premature baby during the & Uncertain & 5 & 12.2 & 2.48 & 82.66 & $\mathrm{H}$ \\
\hline & & Agree & 28 & 68.3 & & & \\
\hline
\end{tabular}




\begin{tabular}{|c|c|c|c|c|c|c|c|}
\hline \multirow[b]{2}{*}{ No } & \multirow[b]{2}{*}{ Item } & \multicolumn{6}{|c|}{ Response Answer } \\
\hline & & & $\mathbf{F}$ & $\mathbf{P}$ & m.s. & r.s. & $\begin{array}{l}\text { Level of } \\
\text { knowledge }\end{array}$ \\
\hline \multirow{3}{*}{10} & \multirow{3}{*}{$\begin{array}{l}\text { the eyes \& genitals must be covered when the premature baby is } \\
\text { placed under the phototherapy }\end{array}$} & Disagree & 1 & 2.4 & \multirow{3}{*}{2.95} & \multirow{3}{*}{98.33} & \multirow{3}{*}{$\mathrm{H}$} \\
\hline & & Uncertain & 0 & 0 & & & \\
\hline & & Agree & 40 & 97.6 & & & \\
\hline \multirow{3}{*}{11} & \multirow{3}{*}{$\begin{array}{l}\text { hand hygiene is very important when a premature baby } \\
\text { care,because the immune system in preterm infants immature so } \\
\text { they are exposed to infection. }\end{array}$} & Disagree & 1 & 2.4 & \multirow{3}{*}{2.95} & \multirow{3}{*}{98.33} & \multirow{3}{*}{$\mathrm{H}$} \\
\hline & & Uncertain & 0 & 0 & & & \\
\hline & & Agree & 40 & 97.6 & & & \\
\hline \multirow{3}{*}{12} & \multirow{3}{*}{$\begin{array}{l}\text { fluid balance (homeostasis) must be carefully monitored for the } \\
\text { premature baby }\end{array}$} & Disagree & 1 & 2.4 & \multirow{3}{*}{2.95} & \multirow{3}{*}{98.33} & \multirow{3}{*}{$\mathrm{H}$} \\
\hline & & Uncertain & 0 & 0 & & & \\
\hline & & Agree & 40 & 97.6 & & & \\
\hline \multirow{3}{*}{13} & \multirow{3}{*}{$\begin{array}{l}\text { it's necessary to wake the premature child every (2-3)hours in the } \\
\text { cause of breast -feeding and every 3-4 hours in the case of bottle } \\
\text { feeding }\end{array}$} & Disagree & 2 & 4.9 & \multirow{3}{*}{2.82} & \multirow{3}{*}{94} & \multirow{3}{*}{$\mathrm{H}$} \\
\hline & & Uncertain & 3 & 7.3 & & & \\
\hline & & Agree & 36 & 87.8 & & & \\
\hline \multirow{3}{*}{14} & \multirow{3}{*}{$\begin{array}{l}\text { the nurse should involve parents and teach them how to care for } \\
\text { premature child and emphasizer on the need for skin adhesion } \\
\text { between the infant and the mother. }\end{array}$} & Disagree & 1 & 2.4 & \multirow{3}{*}{2.95} & \multirow{3}{*}{98.33} & \multirow{3}{*}{$\mathrm{H}$} \\
\hline & & Uncertain & 0 & 0 & & & \\
\hline & & Agree & 40 & 97.6 & & & \\
\hline 15 & premature baby's temperature must be measured every $3-4$ hours & Disagree & 2 & 4.9 & 2.87 & 95.66 & $\mathrm{H}$ \\
\hline
\end{tabular}

$\mathrm{m} . \mathrm{s}=$ mean of score; $\mathrm{r} . \mathrm{s}=$ relative sufficiency; $\mathrm{l}=$ low level of knowledge $(\mathrm{r} . \mathrm{s}=\leq 66.6) ; \mathrm{m}=$ moderate level of knowledge $(\mathrm{r} . \mathrm{s}=>66.6-\leq$ 83.3); h=high level of knowledge (r.s=>83.3).

\section{Discussion}

This chapter presents a systematically organized, interpretation of available related studies. Premature is a live born infant delivered before 37 weeks from the first day of last menstrual period. It accounts for the largest number of admissions to neonatal intensive care unit (NICU). Premature infants can develop a range of problems because their organs are not mature enough.

The present study shows regarding the following:-

The result study show that (61\%) of nurses who are at premature baby section were within the age group of (21-30)years and $(24.4 \%)$ were within the age group of (31-40)years old, (73.2\%) of them were female(53.7\%) were 3 years or less, $(19.5 \%)$ were $(9-13)$ years, $(17.1 \%)$ were (4-8) years and (9.8\%) were (14-18) years.

Concerning to level of education of the study sample, the results demonstrate that's most of them $(4.9 \%),(22 \%)$ and $(70.7 \%)$ were having bachelor of nursing, nursing diploma and junior (preparatory) nursing respectively. Also regard to current place of work, in hospital of the nurses were $(87.8 \%)$ and $(12.2 \%)$ working in neonatal and RCU respectively. Abohmied, Z, 2015 reported that the majority of $60 \%$ of nurse's age between $25-30$ years followed by $26 \%$ there age from $31-35$ years and the gender where almost $86 \%$ of nurses were female. Concerning years of experience where this study was observe that $66 \%$ of nurses had bachelor degree $22 \%$ of sample were post graduate level and $12 \%$ were diploma level and concerning education level where showed that $34 \%$ of nurses between $6-10$ years followed by $32 \%$ were $1-5$ years, $16 \%$ more than 10 years and $18 \%$ less than 1year. Concernning to nursing care,the result shown that nurses have had high level of knowledge in all items. The result was agrees with (Abohmied, Z,2015) in some of items. Where agree in no. 10 show that $94 \%$ of nurses covered eye and genital while phototherapy, in no. 11 showed that $68 \%$ of nurses perform hand hygiene, in no. 12 that $94 \%$ of nurses monitor infant balance carefully, but disagrees in no. 15 show that $50 \%$ of nurses check temperature for baby every hour.

\section{Conclusions}

According to the present study findings, the researchers enabled to make the following conclusions: 
Most of the nurses participated in the study were femal, within age group less than 30 years old. The majority of nurses that participated in this study have a secondary school of qualification in nursing. the experience of majority of nurse who had work at premature department were less than five years. The study revealed high nurse's knowledge regarding complication and ideal caring of premature baby .

Recommendations: According to the results of the study the researcher recommended that: Emphasis on the survival of nurses working in the department where he works and not to change his place of work in order to allow time to gain more experience in the section in which he works and increase information. Emphasize the establishment of scientific courses for the nurses of the department in which he works so that he can gain more experience. Provision of scientific booklet about standard management with clear language. College graduated nurses should be encouraged to working in prem nursing staff must at bachelore degree education level.

Financial Disclosure: There is no financial disclosure.
Conflict of Interest: None to declare.

Ethical Clearance: All experimental protocols were approved under the College of Nursingand all experiments were carried out in accordance with approved guidelines.

\section{References}

1. Kimberly G. Shelov, Stephen P.; Hannemann, Robert E., eds. Caring for Your Baby and Young Child: Birth to Age 5. Illustrations by Wendy Wray and Alex Gray (Revised ed.). New York, NY: Bantam. 1998; 90-47015.

2. Petrou S, Henderson J, Bracewell M, Hockley C, Wolke D, Marlow N. Pushing the boundaries of viability: the economic impact of extreme preterm birth. 2008.

3. Parul D. Pediatric nursing 2end edition : jaypee Brothers.2009.

4. Early H. [PubMed] 18. Krisanne Larimer,. author of "Kangarooing Our Little Miracles. 2006;82:7784.

5. The March of Dimes: Preemies: The Essential Guide for Parents of Premature Babies. Medline Plus: Premature Infant. Baby Magazine, 2008. 